\title{
Core Self-Evaluations, Self-Leadership, and the Self-Serving Bias in Managerial Decision Making: A Laboratory Experiment
}

\author{
Matteo Cristofaro ${ }^{1, *,+(\mathbb{D})}$ and Pier Luigi Giardino ${ }^{2,+}+(\mathbb{D})$ \\ 1 Department of Management and Law, University of Rome 'Tor Vergata', 00133 Rome, Italy \\ 2 Faculty of Economics, University of Rome 'Tor Vergata', 00133 Rome, Italy; \\ pierluigi.giardino@alumni.uniroma2.eu \\ * Correspondence: matteo.cristofaro@uniroma2.it \\ + These authors contributed equally to this work.
}

Received: 16 August 2020; Accepted: 2 September 2020; Published: 3 September 2020

\begin{abstract}
The self-leadership construct has received great attention from scholars over the last 40 years due to its capacity to influence personal effectiveness. However, despite strongly influencing individuals' self-efficacy, performed studies did not determine whether self-leadership is connected, and how, with the Core-Self Evaluation (CSE) trait-a complex personality disposition based on self-efficacy, self-esteem, locus of control, and emotional stability-that has been found impacting decision-making processes within organizations. Moreover, it has not been identified whether individuals with a high level of self-leadership are more prone to be victims of some cognitive biases in decision-making processes, such as the internal attribution of successes and external attribution of failures (i.e., Self-Serving Bias, SSB) that are usually led by the strong belief of individuals in their own capacities. The outlined gaps can be substantiated by the following two research questions: "How is self-leadership related with CSE?" and "How does self-leadership influence the attribution of successes/failures?". To answer these questions, the following were identified and analyzed for 93 executives: (i) the tendency in the attribution of successes and failures, (ii) the CSE, and (iii) their self-leadership level. Results show that: (i) a high level of CSE is connected with high levels of self-leadership; (ii) high levels of self-leadership bring individuals to the internal attribution of successes and external attribution of failures. This work reinforces the stream of (the few) studies that considers a high level of CSE and self-leadership as not always being desirable for managerial decision-making processes and consequent performance. This paper aims to enrich the debate concerning the relations between, on the one hand, self-leadership and, on the other hand, personality traits between self-leadership and decision making.
\end{abstract}

Keywords: self-leadership; core self-evaluations; decision making; self-serving bias; biases; behavioral strategy; personality; cognition

\section{Introduction}

"Self-leadership (Manz 1986; Manz and Neck 2004) is a process through which individuals control their own behavior, influencing and leading themselves through the use of specific sets of behavioral and cognitive strategies" (Neck and Houghton 2006, p. 270). In other words, individuals with high levels of self-leadership are more able, through the implementation of behavioral and cognitive strategies (e.g., mental imagery and positive self-talk), to develop personal effectiveness in their private and working lives (Goldsby et al. 2020). From the first appearance of this construct in 1983 by Manz, a plethora of scholars contributed to the development of self-leadership. The main advancements of 
this construct are related to the positive influence of self-leadership—at the individual level—on job performance (Frayne and Geringer 2000), job satisfaction (Neck and Manz 1996), long-term career success (Murphy and Ensher 2001; Raabe et al. 2007), lower absenteeism (Frayne and Latham 1987), lower work anxiety (Saks and Ashforth 1996), and self-efficacy (Latham and Frayne 1989; Prussia et al. 1998). Regarding the last characteristic, the concept of self-efficacy (i.e., the self-estimation of being successful) is of particular importance to self-leadership (Neck and Houghton 2006). Indeed, according to self-leadership studies (Manz 1986; Manz and Sims 1986; Manz and Neck 2004; Neck and Manz 1992, 1996, 2007; Prussia et al. 1998), one of the most important goals of self-leadership strategies is to increase self-efficacy perceptions in order to reach high performance levels. However, in recent years, self-efficacy has been rediscovered as a main personality trait that is part of a more complex construct strongly influencing the behavior of organizational agents at the workplace as well as their decision-making processes, i.e., Core Evaluations (Judge et al. 1998). This complex personality disposition-formed by self-efficacy, self-esteem, a locus of control, and emotional stability-is responsible for the judgment about other individuals, the external environment, and even themselves (Core Self-Evaluations (CSEs) in this last case; (Judge et al. 1998; Judge and Bono 2001)). Hence, it is posited-in accordance with the established literature that assumed and proved the antecedent role of personality traits with regard to behavior (Ajzen 2005)—-that CSEs are an antecedent of self-leadership. In this regard, and due to the fact that no other contributions, to the best of the authors' knowledge, have been produced on the relationship between CSEs and self-leadership, the following research question emerges to understand how CSEs work as an antecedent of self-leadership: "How is self-leadership related to CSE?".

Moreover, stemming from the fact that it has been proved that high self-efficacy leads to cognitive biases in managerial decision making (Stevenson et al. 2019; Cristofaro et al. 2020), we suggest whether high levels of self-leadership can lead to the occurrence of cognitive errors when making decisions. In particular, due to the already discovered relationship between self-efficacy and Self-Serving Bias (SSB)—also called Self-attribution bias (used interchangeably within the text) —which involves the internal attribution of successes and external attribution of failures (Watt and Martin 1994), a second research questions emerges as follows: "How does self-leadership influence the attribution of successes/failures?".

To answer the two above-mentioned research questions, a laboratory experiment has been conducted with 93 executives, randomly contacted through Amazon Mechanical Turk. In particular, the CSE (Judge et al. 2003), self-leadership (Houghton and Neck 2002), and SSB questionnaires (Libby and Rennekamp 2012) have been administered to the executives, as well as two generic tasks for stimulating their own evaluation of performance (on the basis of SSB). Thanks to the collected data, hypotheses have been tested through two one-way Analysis of Variance (ANOVA). Results of the analysis have revealed that: (i) a high level of CSE is connected with high levels of self-leadership, and (ii) high levels of self-leadership bring individuals to the internal attribution of successes and external attribution of failures (i.e., reductions in the SSB).

This work reinforces the stream of (the few) studies that considers a high level of CSE and self-leadership as not always desirable for managerial decision-making processes and consequent job performance (Barker 1993; Langfred 2004; Hiller and Hambrick 2005). Thus, this investigation enriches debate about: (i) the relationships between self-leadership and personality traits (Manz and Sims 2001; Gilson and Shalley 2004; De Jong et al. 2006; Stewart et al. 2017); and (ii) the relationships between self-leadership and decision making (Houghton et al. 2004; Humphrey et al. 2007; Behfar et al. 2008). In particular, it is advanced that CSEs are an antecedent of self-leadership; thus, the degree of the former personality trait influences the process through which individuals control their own behavior, influencing and leading themselves through.

In fact, this contribution advances that individuals with high levels of self-leadership can be more prone to cognitive errors (Cristofaro et al. 2020). Stemming from these results, practitioners should not only train themselves and others towards the adoption of self-leadership strategies, but also 
engage in mental processes aimed at enhancing reflection on the correctness of these self-leadership strategies and quality of related decisions (see the checklist of (Kahneman et al. 2011)). In other words, the accuracy of decision-making processes of individuals with high self-leadership should be checked even more than that of individuals with a low or medium level of self-leadership; this is due to the fact that the greater the adoption of behavioral and cognitive strategies for positively influencing personal effectiveness, the greater the risk in wrongly interpreting feedback of their own actions if the feedback is not aligned to what has been desired.

The remainder of the paper is as follows. In Section 2, the theoretical background of the work-consisting of CSE, self-leadership, and SSB literature-is provided to the readers of Administrative Sciences. Then, the hypothesis development section is put forward in which the two above-reported research questions are explained in more detail. Section 4 describes the research design, data collection, and data analysis procedures. Section 5 is dedicated to the results produced to verify the developed hypotheses. Finally, discussion of the results in light of prior literature, the implications for theory and practice, and the limitations of the work are provided together with the development of some future research directions.

\section{Theoretical Background}

\subsection{Self-Efficacy and Self-Esteem: A Theoretical Premise}

Albert Bandura (1986) defined self-efficacy as directly related with individuals' beliefs in their own personal abilities, both at physical and mental levels, such as how well they will be capable of managing their skills and cognitive abilities, and how much effort they will be able to carry in order to achieve a predetermined goal. According to Bandura et al. (1999), individuals that have a high level of self-efficacy are more frequently expected to perceive challenging duties as something to be mastered instead of perceiving them as something to be bypassed. Consequently, individuals with a high level of self-efficacy are more inclined to work hard in order to accomplish their duties, even if they have to keep up their endeavors in the long term. However, according to Bandura (1997), the perception of self-efficacy mainly depends on the feedback received from other individuals-as previously stated by Weinberg et al. (1979) — thus: if people receive negative feedback about their physical and mental efficiency, they will perform inadequately, while if they receive positive feedback, they will be likely to show outstanding performances. Yet, this feedback, which determines the perceived self-efficacy, varies according to the situational circumstances of the task that the individual is facing; indeed, Bandura stated that: "The extent to which people will alter their perceived self-efficacy on the basis of performance feedback will depend on such factors as the difficulty of the task, the amount of effort they expend, the amount of external aid they receive, the situational circumstances under which they perform, and their mood and physical state at the time" (Bandura 1986, p. 363). In contrast to this task-related perception of self-efficacy, other scholars have subsequently conceived self-efficacy in a more general dimension that has been called General Self-Efficacy (GSE) (Gardner and Pierce 1998; Judge et al. 1998), which, within this work, is the meaning adopted when speaking about self-efficacy. GSE can be described as the attitude of an individual's belief in one's global capacity to face challenges across a broad range of circumstances (Judge et al. 1998; Scherbaum et al. 2006). This stream of studies assumes that GSE is able to catch distinctive variations among people in their propensity to see themselves as able to manage and achieve different goals in different contexts; thus, GSE is a 'situation-independent context belief' rather than a fluctuant perception of their own abilities. However, GSE and specific self-efficacy are linked by a high inter-relationship (Judge et al. 1998, 1999). Indeed, various studies demonstrated that GSE and specific self-efficacy are positively correlated, as well as the former having been found to be a determinant of the latter (Chen et al. 2001; Scherbaum et al. 2006).

In relation to self-efficacy, other scholars defined and advanced the concept of self-esteem, conceived as the whole set of personal introspective beliefs that people have about themselves as well as their perception about the emotional states affecting both their professional and personal lives (Smith 
et al. 2007). In particular, some scholars (Leary and Baumeister 2000) identified that self-esteem can be used for testing the perception that individuals have about a specific personal quality, i.e., "I believe I am a good student and I feel satisfied about that—or about a global evaluation of themselves-i.e., "I believe I am not a good person, and I feel bad about myself in general". Due to the obvious link between the evaluation that a person can make about her/himself in general or about a specific quality (self-esteem) and the evaluation that the same person can make about her/his abilities (self-efficacy), it has been derived and proved that self-esteem is often directly affected by self-efficacy (Judge and Bono 2001; Lane et al. 2004; Asakereh and Yousofi 2018). Indeed, the perception that people make about their own abilities is influenced by the feedback received from others around them about their reached performance, affecting the perception of their own worth.

Thanks to the huge number of existing studies, self-efficacy and self-esteem are two of the four main personality traits investigated within the domain of industrial and organizational psychology (Judge et al. 1998), which is then aggregated under the same umbrella term (trait), called Core Evaluations.

\subsection{Core Self-Evaluations}

Decision-making processes essentially depend on two intertwined factors: the internal/external environment of the organization and the behavior of the decision maker (Abatecola and Cristofaro 2019). This second cluster includes several variables, like emotions and individual tendencies, i.e., personality traits (Paniccia 2002; Cristofaro 2016, 2017a, 2019, 2020; Busic-Sontic et al. 2017). Among the whole set of individual tendencies, scholars have identified four elements, i.e., self-efficacy, self-esteem (the general esteem an individual has with respect to himself/herself), locus of control (i.e., the conviction in controlling life's variables), and emotional stability (the capacity to maintain a low neuroticism level), which have a proved capacity of mainly affecting decision-making processes within organizations (Judge et al. 1998).

Judge et al. (1998) exemplified that these elements are completely inter-related, resulting in the conceptualization of Core Evaluations (CE), a complex trait that is responsible for judgment about other individuals, the external environment, and even themselves-in this last case, it is referred to as Core Self-Evaluations or simply CSEs (Judge et al. 1998; Judge and Bono 2001). The investigations done by the adoption of the CE construct consider, in practice, the main role of the 'human factor' in the workplace (Judge et al. 2009). In this regard, research that has used this construct arrived at the conclusions that if the decision maker judges himself/herself extraordinarily high in this construct (i.e., high CSE) he/she will be extremely confident about competences, decision-making skills (Hollenbeck et al. 1988; Judge et al. 1998; Judge and Bono 2001; Silvester et al. 2002), job commitment (Erez and Judge 2001), career performance, goals reached, earnings, and job-related prominence (Judge and Hurst 2008). Basically, the CSE construct delineates that people who are extremely confident in their skills and persevere in their long lasting efforts towards their goals, are driven to reach impressive results in their work experience, receiving huge earnings and also playing out illustrious roles in society (Cristofaro 2017b).

Following the above-mentioned studies, Hiller and Hambrick (2005) were the first to delve deeper into the connections between top mangers' $\mathrm{CE}$ and the strategy of organizations; from this research, scholars expected that top managers with a high level of CSE would reveal this innate personality factor in their performance in the workplace. In particular, it has been assumed that executives with a high degree of CSE strongly consider their skills as the main contributing factor to achieve great job performance. This assumption lies in the belief that executives with an extraordinarily high degree of CSE are, generally, less prone to anxiety, also showing less concern with respect to pessimistic forecasts because there is the belief that they can overcome adversities and solve all the problems they are called to face. In conclusion, hyper-CSE top managers are self-confident in their ability to triumph in both professional and personal circumstances.

In recent years, a growing number of studies in management and organization have investigated the CSE construct. For example, Wang and Xu (2019) found, through the study of 377 employees, that ethical leadership is effective in eliciting work meaningfulness and attitudes for employees with 
higher CSE or when perceived organizational support (POS) is lower, and is ineffective for those with lower CSE or when POS is higher. Yet, Zhang et al. (2020) discovered, using a sample of 200 researchers and their supervisors, that employee knowledge sharing behavior works as a mechanism that links CSE to creativity. In particular, they identified the novel moderating role of work meaningfulness in the relationship between CSE and knowledge sharing and the indirect effect of CSE on creativity due to knowledge sharing.

Few studies, however, have inspected the link between CSE and decision-making process variables. One of these is the contribution of Cristofaro et al. (2020) through the test of a sample population of 120 Master's degree students who were involved in a business game and were challenged in making strategic choices (in teams) playing the role of executives of a small-sized corporation. The authors found that a huge level of CSE is positively related to an intuitive decision-making process and a high degree of performance in the workplace. However, they also found that teams having a medium level of CSE obtained greater results than teams with high CSE. Moreover, they also found that having a significant degree of CSE can lead to a fall in behavioral biases. In sum, this recent study significantly undermined the established view that there is only a positive relationship between $\mathrm{CE}$ and organizational agents' behavior in the workplace.

\subsection{Self-Leadership}

The self-leadership concept first appeared in a 1983 practitioner-oriented book (Manz 1983), but it was only in 1986 that Manz formally defined it as the process through which individuals control their own behavior, influencing and leading themselves through the use of specific sets of behavioral and cognitive strategies. It is worth stating from the beginning that self-leadership is distinct from the concept of autonomy; indeed, the latter is a need, together with freedom, which forms the basis for self-leadership (Stewart et al. 2019). These two, therefore, are variables that are inter-related with each other, but do not underline the same phenomena; on the contrary, they should be well combined in order to avoid dysfunctional results (Langfred 2005). On this relationship between self-leadership and autonomy, through the study of 71 self-managed teams composed of MBA students, Langfred (2004) found that members of self-leading teams are generally reluctant to monitor each other given their effort to maintain high individual autonomy, which leads to poor performance when individual autonomy is high and to excellent performance when individual autonomy is low. In another study of longitudinal data from 35 self-managing teams, Langfred (2007) confirmed that very high self-leadership undermines individual autonomy, thus further advancing a negative relationship between self-leadership and autonomy.

The behavioral and cognitive strategies of self-leadership are designed to positively influence personal effectiveness, which is necessary to accomplish both private and professional goals (Manz 1986; Manz and Neck 2004). Then, in 1987, the first empirical study was conducted to examine self-leadership in an organizational setting, which aimed to examine the role of self-leadership in the context of both empowering leadership and self-managing teams (Manz and Sims 1987). This latter study suggested that the most effective external leaders of self-managing work teams are those that engage in behaviors that facilitate self-leadership strategies, such as self-observation, self-goal setting, and self-reward-therefore firstly proving the positive effect of self-leadership in management and organizational activities.

A few years later, self-leadership's 'thought pattern strategies' were more fully developed and expanded under the label "thought self-leadership", which is the method that facilitates employees in reaching goals of wellbeing and superior efficiency, especially when facing dynamic work scenarios through focusing on the beneficial sides of a diversified labor force (Manz and Neck 1991; Neck and Manz 1992). The practical usefulness of the more fully developed thought self-leadership strategies was later demonstrated in a training-intervention based on field study (Neck and Manz 1996). The results of this contribution suggest that individuals who received the thought self-leadership training experienced increased mental performance, increased positive affect (enthusiasm), increased 
job satisfaction, and decreased negative affect (nervousness) relative to those not receiving the training (Neck and Manz 1996).

Self-leadership strategies are commonly classified intothree essential groups: (i) behavior-focused strategies, (ii) natural reward strategies, and (iii) constructive thought pattern strategies (Manz and Neck 2004; Manz and Sims 2001; Prussia et al. 1998). The first category seeks to enhance the personal self-awareness with the aim of assisting behavioral management, particularly when people have to face indispensable but obnoxious duties (Manz and Neck 2004). In a nutshell, the strategies belonging to the first listed category, on the one hand, are constructed to stimulate positive and useful performances aimed to achieve advantageous outcomes and, on the other hand, they are designed to mitigate the impact of unfavorable attitudes that could generate disastrous outcomes (Neck and Houghton 2006).

The second category listed strategies related with scenarios where people are stimulated or remunerated by intrinsically pleasant features of the duties they are called to manage (Manz and Neck 2004; Manz and Sims 2001). Several investigations showed that there are two dominant natural reward approaches. The first approach is associated with the creation of gratifying elements in a specific set of activities to perform, so that the duties easily become worthwhile (Manz and Neck 2004; Manz and Sims 2001). The second approach concerns the methodology of shaping feelings by shifting the focus from the negative to the most fruitful feature of the duty to accomplish (Manz and Neck 2004; Manz and Sims 2001). Both approaches are inclined to generate awareness of proficiency and self-determination, which constitute two fundamental methods of self-motivation. In summary, the strategies in the second category are aimed to foster feelings that serve to empower task-related performances (Neck and Houghton 2006).

The third category is designed to group all the methods aimed to promote the creation of constructive thought patterns and automatic shortcuts that can effectively affect performances (Manz and Neck 2004; Neck and Manz 1992). Constructive thought pattern strategies concern the analysis of defective knowledge, mental symbolism, and positive self-talk. In fact, people who foresee profits coming from the accomplishment of a task are more inclined to approach it with a positive and successful mindset (Manz and Neck 2004). This concept was investigated by Driskell et al. (1994) when conducting a meta-analysis of 35 experimental tests aiming to support the impact of the third category of self-leadership strategies.

Manz (1986) introduced a new point of view, indicating that the self-leadership mechanism starts when people measure the ongoing conditions of an event against self-set expectations concerning the same scenario analysis. Even if the course depicted by Manz (1986) is related with the organizational control systems in broad terms, when it affects self-leadership, the mechanism of supervision is basically self-imposed instead of being administered externally. Under this lens, self-leadership can literally be depicted as an essential decisive, even core, feature of both organizational psychology and behavior (Stewart et al. 2019).

Apart from analyzing the effects of self-leadership in organizations, scholars have also investigated the antecedents of self-leadership, both at the individual and group levels; these forces can be mainly classified by their nature, i.e., internal or external (Stewart et al. 2011). With regard to internal antecedents, at the individual level, studies have demonstrated that they are crucial for individual self-leadership, such as internal or natural rewards and 'thought self-leadership' (a means for individuals to manage their own thinking tendencies). In particular, people who choose their work position with internal or natural rewards or embed their career with spontaneously exciting duties are expected to be self-leading in the workplace (Neck and Manz 1996). Furthermore, internal antecedents of self-leadership can also be found at the group level; in fact, if within the group there is a high degree of cohesion, both benefits and penalties are more likely to become self-reinforcing (Barker 1993; Stewart et al. 2012). Yet, numerous external antecedents have an impact both at the individual and group level of self-leadership. At the individual level, for instance, Stewart Greg L. and Cardy (1996) demonstrated that self-leadership coaching was notably beneficial for those people who have a low level of scrupulousness (Frayne and Geringer 2000; Frayne and Latham 1987; Latham and Frayne 
1989). Another important source of external antecedents comes from the national culture, which leads people to have considerable discrepancies in the adoption of self-leadership, and it also touches the intrinsic connotation of self-leadership inside that specific national scenario (Stewart et al. 2019). For example, Neubert and Wu (2006) found that certain self-leadership strategies, such as self-goal setting, were more adopted in the Chinese context rather than in Western countries, while other self-leadership strategies, such as self-observation, were more used in Western countries rather than in China.

Moreover, apart from national cultural norms, the structure of the organization is also very important; in fact, it can represent a clear example of external antecedents, as investigated by Manz et al. (2009). In particular, they found that groups that work in a context of high-involvement, as well as those in organizations that have a lower degree of centralization and formalization, have a better chance to be effective in terms of self-leadership, especially if they are based on a benefit mechanism architecture in which they are likely to be effective promoters of self-management.

Abundant research has disclosed the beneficial consequences of self-leadership on the results coming from the work environment, both at individual and group levels (Cohen et al. 1997; Manz and Sims 1987; Uhl-Bien and Graen 1998). At the individual level, it appears that self-leadership is a crucial element to achieve outstanding career achievements (Murphy and Ensher 2001; Raabe et al. 2007). In fact, a high level of self-control has been explicitly associated to a positive employee's mindset and feelings, e.g., low mental pressure and apprehension-with the consequence of increasing the degree of self-efficacy (Latham and Frayne 1989; Prussia et al. 1998; Saks and Ashforth 1996). Thus, it can be deduced that self-leading workers are likely to have a prosperous career directly related to their expected higher degree of productivity, commitment (Stajkovic and Luthans 1998), and job gratification (Neck and Manz 1996; Uhl-Bien and Graen 1998) as well as a lower level of absenteeism from the workplace (Frayne and Latham 1987; Latham and Frayne 1989).

At the group level, the consequences of self-leadership on performance results are not fully definitive; in fact, the beneficial effects concerning the implementation of self-leading groups have been supported in some studies on group level productivity (Cohen and Ledford 1994; Cordery et al. 1991; Elmuti and Kathawala 1997; Fredendall and Emery 2003; Stewart and Barrick 2000; Trist et al. 1977; Wall et al. 1986). However, another stream of scholars has not depicted, generally, such a positive level of performance from the formation of groups with high self-leadership. For instance, DeVaro (2006) found that meticulously coached groups produce results comparable to those of groups with a high degree of self-control. Yet, a meta-analysis, made from the outcomes of eight tests and performed by Combs et al. (2006), showed that just a moderate connection existed from implementation of self-leadership in groups and their level of efficiency in achieving their planned goals. To conclude, while outcomes from the analysis of the effects related to the application of the self-leadership methodology at the individual level mostly agree with the benefits derived, at the group level the results hint that self-leadership may not be directly related with positive repercussion on productivity and efficiency (Stewart et al. 2011).

\subsection{Self-Serving Bias}

A 'bias' represents divergence from what is identified as a rational decision (Kahneman and Tversky 1974) and this general classification of deviations from rationality is adopted for both cognitive traps (i.e., mental inaccuracies) and heuristics (i.e., cognitive shortcuts) (Cristofaro 2017a, 2018). The first category, cognitive traps, was originally and properly described by Hammond et al. (1998). In particular, these scholars identified the frequently occurring traps, such as the anchoring trap, causing top managers' wrong judgment about the decisions to take. The second category, heuristics, was firstly conceptualized by Kahneman and Tversky $(1974,1979)$ in their heuristics and biases' research program. Their behavioral tests showed that rational shortcuts arise in decisions characterized by unclarity or complexity, derived from the presence of enormous, or insufficient, quantities of information to bear in mind during the decision-making process (Kahneman and Tversky 1974, 1979).

Nevertheless, traps and heuristics produce different outcomes affecting the decision-making process. In fact, the results of some research showed a constantly negative impact coming from 
traps, while heuristics are characterized by alternating positive/negative impacts (Abatecola et al. 2018). Additionally, thanks to the ecological rationality view and research program of Gigerenzer and Todd (1999), heuristics have been found to lead, in some circumstances and under some conditions, to superior judgments rather than to adopting complex approaches in order to drive a decision (e.g., logistic regression; Luan et al. 2019).

Among biases, one of the most studied ones has been the Self-Serving Bias (SSB) (Abatecola et al. 2018). Heider (1958) is considered as the scholar who first articulated the concept of self-serving bias (SSB), recognizing that in scenarios characterized by uncertainty, human behavior is affected by mental strategies which aim to protect or enhance individuals' self-perceptions (Greenberg 1991; Greenwald 1980; Greenberg et al. 1982; Sedikides et al. 1998; Sedikides and Strube 1995, 1997; Weary-Bradley 1978, 1979; Zuckerman 1979). In particular, SSB occurs when people assign personal credit to their achievements, while they assign the causes of their failures to external factors-a phenomenon that diffusely affects human behavior, as demonstrated by Campbell and Sedikides (1999) and Allen et al. (2020) in their meta-analysis of a large segment of research about SSB. Individuals that fall into the SSB usually have a high level of self-confidence, which depicts them as being more competent than they are in reality, leading to exceedingly rosy plans for the future. Larwood and Whittaker (1977) originally proved this relationship within two teams, respectively comprising management undergraduates and corporate executives. It appeared that the undergraduates constantly overvalued their skills during the marketing simulation game; those students were confidently arguing that the imaginary firm they were running would rapidly overwhelm their competitors. Equally, the executives were also envisioning incredible achievements; nevertheless, they were mitigating the forecast if the previous planned outcomes were inadequate. Libby and Rennekamp (2012) found similar results by demonstrating that people affected by self-serving attribution address greater importance to internal rather than external factors to achieve outstanding results. This attitude heightens trust in their own capabilities, which are directly related to their enthusiasm and confidence in betting on the future. In addition, Libby and Rennekamp (2012) found that other traits, such as dispositional optimism and miscalibration, also strengthen the degree of confidence in enhancing forthcoming predictions of future earnings and performances and in their different attributions according to the outcome presented. Yet, Chin et al. (2018)analyzed the link between SSB and the better-than-average effect (BTA) —evaluating themselves more positively than they evaluate most other people-as well as its consequences on trading choices. Their analysis was aimed to assess methods to diminish the behavioral and trading biases in financial market activities. Chin et al. (2018) have found that people with SSB show a higher level of BTA compared with those affected by the absence of SSB. In brief, SSB and confidence, within their own capabilities, are two inter-related phenomena that influence each other and do not lead to a rational assessment of performance.

Moreover, apart from the influence of other personal traits, the manifestation of SSB has also been found to be connected with external environment changes. In this vein, Keusch et al. (2012) investigated the impact of SSB in the annual reports addressed to the investors of most highly capitalized European corporations between 2006 and 2008. The conclusions emanating from their investigation indicated that during a period of crisis, executives have a greater propensity to adopt SSB attitudes than in a period of no crisis. Furthermore, in discordance to the conclusions stated by D'Aveni and MacMillan (1990), Keusch et al. (2012) revealed that acclaiming and defensive ascription behaviors are undoubtedly adopted more during a period of crisis rather than when the economic, financial, and organizational equilibrium of a company is under control. Regarding the allusions about the external environment, the outcomes presented by Keusch et al. (2012) indicated that in 2008, corporations adopted much more justifications associated with the external environment than in 2006 . Thus, these outcomes clearly suggest that the elements coming from the external environment were manipulated in order to separate executives' conduct from the negative results that occurred and, consequently, highlighted their ability to produce effective results, regardless of the adverse external environment. 


\section{Hypothesis Development}

Hayward and Hambrick (1997) adopted an overall hubris index, very sensitive to the variation of hubris, in order to measure a wide range of variables related with fortuitous events and individuals' behaviors, indicating the necessity for a psychometrically founded and recognized construct for considering the uncommon self-confidence in many top managers. In this regard, Hiller and Hambrick (2005) defined hyper-CSE (a very high level of CSE) as the useful variable to accurately test that construct. The apogee limit of CSE may be contemplated as a meticulously confirmed 'hubris factor'-substantiating a strong belief of top managers in their own capacities and building their own future. This has been empirically found, despite investigating potential employees rather than executives, by Wanberg et al. (2005). In particular, these scholars conducted sample tests on a large group of job seekers in order to analyze their behavior in a very stressful situation, such as unemployment. From their research, it appeared that CSE directly affects perseverance in looking for a job position: a high level of CSE is beneficial for showing above average levels of persistence when searching for employment over the period of unemployment. Thus, a high level CSE can, doubtless, be related with a more positive attitude to face situations that undermine the mind and the spirit of people - or at least it appears to be so according to recruiters' perceptions (Cristofaro 2017b).

Continuing along the link between CSE and self-development, Kim et al. (2012) inspected if and how CSE influences learning inclination and efficiency. In particular, through a lengthwise model and data collected from a sample of over 600 undergraduates, Kim et al. (2012) demonstrated that CSE truly and positively influences self-efficacy $(r=0.33)$, the learning target level $(r=0.15)$, and the learning target commitment $(r=0.38)$. In other words, CSE is an antecedent of self-development within the learning context. Similarly, McKinney (2014) investigated a sample group of over 300 undergraduates from several US universities in order to inspect whether the levels of goal orientation and CSE are complementary to undergraduates' Grade Point Average (GPA), study routine, and learning performance. Results of the analyses showed that goal orientation and CSE are pivotal predictors of students' performance due to the positive correlation among these variables. In addition, McKinney (2014) pointed out some intriguing conclusions, such as the fact that goal orientation and CSE causes additional improvement to the undergraduates' performance, exceeding the self-regulatory variables. In other words, the person who reaches the greatest values in self-regulation is also a person with a high level of CSE. This last statement also finds support in the work of Paunova (2017) who, through the investigation of more than 200 people from 46 nationalities employing 36 self-managed groups, concluded that both language skills and CSE are related with an increase in leadership status. In fact, team members seek to appoint, as group leaders, people who embody the idea of a leader (Bass and Stogdill 1990), notably when they have particular skills such as dynamism, extreme ownership, confidence, and, last but not least, linguistic proficiency. Thus, Paunova (2017) demonstrated that people who gain high positions inside multinational teams are characterized by a high level of CSE, which undoubtedly affects the positive link between their linguistic competence and leadership status. CSE is also related to measures of persistence in individuals' leadership goals at both a personal and professional level (i.e., self-development); in this latest case, this relationship involves an increase in the leadership status. In this regard, it is worth noticing that self-development and orientation to accomplish both private and professional goals (Manz 1986; Manz and Neck 2004) can be found at the basis of the self-leadership concept. Accordingly:

Hypothesis 1 (H1). Individuals with high CSE have greater self-leadership compared to individuals with low and average CSE.

Silver et al. (1995) investigated the link between job performance and outcome attribution-the basis of SSB - through the mitigating effect of self-efficacy. In doing so, they delivered practical problems, similar to those presented during the Graduate Management Admission Test (GMAT) exams, to a sample of 100 undergraduate students. The results of this investigation revealed the 
importance of reaching high levels of job performance and of how people understand the reasons for their performance. In fact, it appeared that different self-efficacy expectations emerge in divergent acknowledgments of performance, directly affecting the guesses: outstanding performances are associated with subjective aspects that boost the self-beliefs of efficacy; negative performance, instead, leads to a decrease in self-belief (Watt and Martin 1994). Thus, from the study carried out by Silver et al. (1995), we can hypothesize that when people truly believe in their capabilities-thus demonstrating a high level of self-efficacy (at the basis of the CSE) - and they achieve successful goals both in their private and professional lives, they are automatically more likely to experience SSB bias than people with an average-medium level of CSE. Yet, Campbell and Sedikides (1999), who collected data from over 6900 participants, studied the effects of the SSB in the workplace, also investigating a wide range of moderators, such as self-esteem, locus of control, gender, and job position. In particular, this study showed that people, according to their level of self-esteem, react in a different manner when they have to face negative outcomes: those with a high level of self-esteem are likely to behave more defensively (Baumeister et al. 1993, 1996; Blaine and Crocker 1993), embodying this defensiveness via an emphasized level of SSB. In contrast, people with a small degree of self-esteem did not fall into the SSB. Another important moderator element investigated by Campbell and Sedikides (1999) concerns success ambition. In fact, these scholars demonstrated that people with a large degree of success ambition-a personal orientation towards self-leadership-are affected by high levels of self-threat, leading them to be more likely to fail in SSB. Implicitly, stemming from the fact that self-esteem is one of the four dispositions at the basis of the CSE trait, we can assume that people with a high level of CSE are inclined to allocate the responsibility of their failures to external factors.

An important element to bear in mind when scholars want to assess the inclination of individuals to be victim of SSB involves self-enhancement-which represents a whole set of mental activity actions aimed to establish, preserve, or augment a positive self-image (Kwan et al. 2004) —at the basis of the self-leadership concept. Hence, some scholars investigated the impact of self-enhancement on the private and professional lives of people (Dunning 1999; Taylor and Brown 1988). For example, Sedikides (1993) showed that people pursue self-knowledge, a pillar of self-enhancement, in order to achieve laudatory outcomes, leading to internally attributing successes and externally attributing failures. Hence, from the work of Sedikides (1993), it can be again derived that people with high self-enhancement, which are thus strongly oriented towards self-leadership, tend to internally attribute success and externally attribute failures.

Finally, it is worth noticing that the SSB is a viable trait for manifesting both self-enhancement and self-protection (Campbell and Sedikides 1999; Mezulis et al. 2004). In fact, Sedikides and Alicke (2012) argued that this aspect, on the one hand, requires taking more consideration than one merits for positive results (i.e., self-enhancement) and, on the other hand, fails to take sufficient liability for negative results (i.e., self-protection). Thus, the attempt to boost the benefits of positive results of their own actions is directly connected with self-enhancement, with the consequential increase in the perception that individuals have of their own abilities. In contrast, attempting to deflect responsibility for negative results is correlated with self-protection, which can be perceived as the aim of not reducing their self-esteem and, consequently, the evaluation that people make about them. From what has just been reported and stemming from the fact that: "A major objective of all self-leadership strategies [...] is the enhancement of self-efficacy perceptions in advance of higher performance levels" (Neck and Houghton 2006, p. 279), it can be derived that:

Hypothesis 2 (H2). Individuals with great self-leadership are more inclined to be victims of the self-serving bias compared to individuals with low and average self-leadership. 


\section{Methodology}

To test the three developed hypotheses and answer the research paper's aim, 93 managers (50 male, 43 female, Average Age $=39.3$ years, Standard Deviation $(\mathrm{SD})=1.9$ years, Average working experience at a managerial position: 8.2 years, Standard Deviation $(\mathrm{SD})=1.1$ years) were sampled through Amazon Mechanical Turk. In particular, Amazon Mechanical Turk is a "crowdsourcing marketplace that makes it easier for individuals and businesses to outsource their processes and jobs to a distributed workforce who can perform these tasks virtually. This could include anything from conducting simple data validation and research to more subjective tasks like survey participation, content moderation, and more" (Mturk 2020). Due to its features, this platform has been extensively used by scholars for collecting reliable responses for experiments on executives (Paolacci et al. 2010).

In line with other similar works (Cristofaro et al. 2020) in research fields at a stage of development far from the nascent one (Edmondson and McManus 2007), the laboratory experiment followed by quantitative analysis has been considered as the most suitable research design. Emerging from reviews on self-leadership, such as Neck and Houghton (2006), these intermediate or mature fields of research—like the role of personal traits in self-leadership—are challenged by "focused questions and/or hypothesis relating existing constructs" (Edmondson and McManus 2007, p. 1260). Each participant of the experiment was administered with the 12-item CSE Scale (CSES) (Appendix A) to measure their CSE degree, the 35-items of the Revised Self-Leadership Questionnaire (RSLQ), the Cristofaro (2016) managerial task, and the Self-attribution bias questionnaire of Libby and Rennekamp (2012). In particular, the measurement of variables at the center of the developed hypotheses was measured as follows.

Core Self-evaluations: The CSE score of each manager was derived by asking participants to complete the 12-item Core Self-Evaluations Scale (CSE by (Judge et al. 2003) reported in Appendix A; test-retest accuracy was 0.81 over a one-month span). This scale provides an explicit and integrative estimation of a person's core self-evaluation. In particular, each participant was asked to rank their predisposition on the 12 items according to a five-point Likert scale ranging from 1 (strongly disagree) to 5 (strongly agree) - values assigned to reverse grade questions were subtracted. The maximum and minimum values that can be reached by completing the CSE are, respectively, +24 and -24 , with a neutral point at 0 . Similar to Cristofaro et al. (2020), thanks to the STATA function called 'egen', it was possible to derive three main clusters according to the average CSE value of managers: (i) low CSE managers (whose averages range from -24 to -9), (ii) average CSE managers (whose averages range from -8 to +8 ), and (iii) high CSE managers (whose averages range from +9 to +24 ). Thanks to the implementation of this STATA function, the initial sample of 93 managers was reallocated in the afore-mentioned three clusters, equating to 31 individuals each.

Self-leadership: Self-leadership was measured with the Revised Self-leadership Questionnaire developed by Houghton and Neck (2002) consisting of 35 items, which refer to their own behavior while at work (they established reliability equal to 0.74 and construct validity). The definition and items are also shown in Appendix B. All items were measured using a five-point Likert scale: $1=$ definitely not true, $2=$ not true, $3=$ neither true nor untrue, $4=$ true, and $5=$ definitely true. Also in this case, the 'egen' STATA function ${ }^{2}$ was implemented in order to derive three main clusters based on the average self-leadership value of managers: (i) low self-leadership managers (whose averages range from 35 to 81), (ii) average self-leadership managers (whose averages range from 82 to 128), and (iii) high self-leadership managers (whose averages range from 129 to 175). The initial sample of 93 managers was reallocated in the previously mentioned three clusters, which in this case also equate to 31 individuals each.

\footnotetext{
Computed as: egen CSE $=$ cut $(\mathrm{CSE})$, at $(-9,8,24)$.

Computed as: egen CSE $=$ cut $(\mathrm{CSE})$, at $(81,128,175)$.
} 
Managerial task: in order to track the internal or external attribution of performance by managers, a managerial task has been administered to participants. In particular, the dynamic multi-step business case developed by Cristofaro (2016) was adopted-face validation and the inter-rater agreement were found to be very positive (Kappa $=0.91(p<0.001), 95 \%)$, while test-retest showed a correlation equal to 0.79 . The managerial task substantiated by the dynamic multi-step business case consisted of the following: a respondent appointed as Chief Executive Officer (CEO) of a leading manufacturing firm in the Italian clothes market, who was going to meet CEOs of the three main competitors at the industry's annual meeting. Before the meeting, the CEO was provided with the last-quarter's financial statement. In contrast to the high level of appreciation among customers, their own firm showed bad performance in terms of revenues and the first cue given to the CEO was that maybe some of the other firms had applied unfair business practices that led them to gain higher revenues at the expense of their own firm. Participants were asked to identify, through answers to a series of investigative questions, where the bad revenue performance must have been ascribed to their own firm or to the unfair business practices of other enterprises. The best performers, in this particular case, are those who after collecting disconfirming cues about unfair business practices, arrived at the conclusions that further investigation would have been needed on the efficacy of their own marketing and sales strategy; this is called 'adaptive behavior'. All the other potential behaviors-(i) fixed: stuck at investigating just one firm and concluded the case accusing a competitor's CEO of unfair business practices, (ii) vagabonding: investigating the business practices of different firms but at the end of the case having accused a competitor of unfair business practices, and (iii) stalled: investigating different competitors' business practices and then being unable to formulate a solution hypothesis to the problem and appointing the general manager to make the decision-were considered as being 'failures'. At the end of the task, participants were advised of their behavior and the Self-attribution bias questionnaire was administered.

Self-attribution bias: In line with Libby and Rennekamp (2012), four responses from each participant were collected aimed at measuring relative weighting on internal attributions (i.e., skill and effort) versus external attributions (i.e., luck and difficulty) for the above described managerial task. The 93 managers involved were asked to provide ratings on four 9-point bipolar scales, each one aimed at discovering the attitude towards internal attribution of performance against an external attribution (i.e., Luck vs. Skill, Difficulty vs. Effort, Difficulty vs. Skill, and Luck vs. Effort). A high value (the highest value is 36) indicates greater internal attribution, while a low value (the lowest value is 4 ) indicates a greater external attribution. According to Libby and Rennekamp (2012), if managers are biased, "those who believe that they performed relatively well (poorly) should be more likely to attribute their performance to internal (external) factors. Furthermore, those who perform well and attribute the performance to internal factors should be more confident about their future performance" (p. 209).

Data analysis: To test the two developed hypotheses, in line with similar works (Cristofaro et al. 2020), the authors conducted two one-way Analysis of Variance (ANOVA). This is the most suitable statistical technique that can be used in order to compare the means of two or more samples to find significant differences, if there are any (Field 2013).

\section{Results}

\subsection{Results for Research Question 1}

To identify whether managers with high CSE have greater self-leadership compared to individuals with low and average CSE (H1), a one-way ANOVA was implemented considering the different CSE clusters (low, average, high), and their results on the RSLQ. This test helps to answer research question 1: "How is self-leadership related with CSE?".

Table 1 shows the results of this test: there is a statistically significant difference between groups as determined by the one-way ANOVA $(\mathrm{F}(2,90)=75.342, p=0.000)$. Then, a Tukey post hoc test (see Table 2) revealed that managers with high CSE have greater self-leadership compared to individuals 
with a low rating $(+6.1 ; p=0.00)$ and average CSE $(+4.9 ; p=0.00)$. So, H1 was verified. Moreover, apart from the relationships just highlighted, it can be derived from Table 2 that: (i) managers with average CSE have greater self-leadership compared to individuals with a low rating $(+2.6 ; p=0.00)$, but lower than self-leadership managers with high CSE $(-4.9 ; p=0.00)$; and (ii) managers with low CSE have lower self-leadership compared to both individuals with an average rating $(+2.6 ; p=0.00)$ and high CSE $(-6.1 ; p=0.00)$.

Table 1. ANOVA Table-Core personality traits substantiating self-evaluation (CSE) on self-leadership.

\begin{tabular}{cccccc}
\hline & Sum of Squares & df & Mean Square & F & Sig. \\
\hline Between Groups & 98.433 & 2 & 48.673 & 75.342 & 0.000 \\
Within Groups & 16.112 & 90 & 0.522 & & \\
Total & 114.555 & 92 & & & \\
\hline
\end{tabular}

Table 2. Post-hoc test-CSE on self-leadership.

\begin{tabular}{ccccccc}
\hline \multirow{2}{*}{ (I) CSE } & (J) CSE & Mean Difference (I-J) & Std. Error & Sig. & \multicolumn{2}{c}{ 95\% Confidence Interval } \\
\cline { 5 - 6 } & & & & Lower Bound & Upper Bound \\
\hline \multirow{2}{*}{ Low CSE } & Average CSE & $-2.60000^{*}$ & 0.3135 & 0.000 & -11.232 & -1.888 \\
& High CSE & $-6.10000^{*}$ & 0.3135 & 0.000 & -14.654 & -3.034 \\
Average CSE & Low CSE & $2.60000^{*}$ & 0.3135 & 0.000 & 1.888 & 11.232 \\
& High CSE & $-4.90000^{*}$ & 0.3135 & 0.000 & -23.819 & -1.181 \\
High CSE & Low CSE & $6.10000^{*}$ & 0.3135 & 0.000 & 3.034 & 14.654 \\
& Average CSE & $4.90000^{*}$ & 0.3135 & 0.000 & 1.181 & 23.819 \\
\hline
\end{tabular}

* The mean difference is significant at the 0.05 level.

\subsection{Results for Research Question 2}

A second one-way ANOVA was conducted in order to verify whether individuals with high self-leadership are more inclined to be victims of the SSB compared to executives with low and average self-leadership (H2). This test helps to answer research question 2: "How does self-leadership influence the attribution of successes/failures?". In doing that, the authors considered the different self-leadership (SL) clusters (low, average, high) and their average answers to the SSB questionnaire of Libby and Rennekamp (2012).

As reported in Table 3, there was a statistically significant difference between groups as determined by the one-way ANOVA $(\mathrm{F}(2.90)=222.176, p=0.000)$. As with H1, in this case also a Tukey post hoc test (shown in Table 4) followed the ANOVA; this second analysis showed that managers with high self-leadership were more inclined to fall into the SSB compared to managers with average self-leadership (+9 points of self-attribution compared with them; $p=0.00$ ) and low self-leadership $(+17$ points of self-attribution compared with them; $p=0.00)$. In other words, executives with high self-leadership had the tendency to attribute performance internally when they are positive and to attribute performance externally when they are negative. So, H2 was verified.

Table 3. ANOVA Table-self-leadership on SSB.

\begin{tabular}{cccccc}
\hline & Sum of Squares & df & Mean Square & F & Sig. \\
\hline Between Groups & 3.320 & 2 & 2.280 & 222.176 & 0.000 \\
Within Groups & 0.109 & 90 & 5.321 & & \\
Total & 3.429 & 92 & & & \\
\hline
\end{tabular}


Table 4. Post-hoc test-CSE on Self-Serving Bias (SSB).

\begin{tabular}{|c|c|c|c|c|c|c|}
\hline \multirow[b]{2}{*}{ (I) $\mathrm{SL}$} & \multirow[b]{2}{*}{ (J) SL } & \multirow[b]{2}{*}{ Mean Difference (I-J) } & \multirow[b]{2}{*}{ Std. Error } & \multirow[b]{2}{*}{ Sig. } & \multicolumn{2}{|c|}{$95 \%$ Confidence Interval } \\
\hline & & & & & $\begin{array}{l}\text { Lower } \\
\text { Bound }\end{array}$ & $\begin{array}{l}\text { Upper } \\
\text { Bound }\end{array}$ \\
\hline \multirow[t]{2}{*}{ Low SL } & Average SL & -7.000 & 1187.12 & 0.612 & -12.112 & 2.433 \\
\hline & High SL & $-17.000 *$ & 1187.12 & 0.000 & -23.443 & -13.657 \\
\hline \multirow[t]{2}{*}{ Average SL } & Low SL & 7.000 & 1187.12 & 0.612 & -2.433 & 12.112 \\
\hline & High SL & $-9.000 *$ & 1187.12 & 0.000 & -10.677 & -7.432 \\
\hline \multirow[t]{2}{*}{ High SL } & Low SL & $17.000 *$ & 1187.12 & 0.000 & 13.657 & 23.443 \\
\hline & Average SL & $9.000 *$ & 1187.12 & 0.000 & 7.432 & 10.677 \\
\hline
\end{tabular}

* The mean difference is significant at the 0.05 level.

\section{Discussion and Implications}

This work attempts to enrich, respectively, the established and nascent debates on the following relationships: (i) self-leadership and personality traits, and (ii) self-leadership and decision making. In particular, this work explores how self-leadership is related with the evaluation of core personality traits substantiating self-evaluation (CSE), and how self-leadership leads to cognitive errors in managerial decision making - this work has also considered the Self-Serving Bias (SSB). In fact, this paper tries to answer the following two research questions: "How is self-leadership related with CSE?" and "How does self-leadership influence the attribution of successes/failures?". In order to do so, the investigation included the testing of three variables: CSE, self-leadership, and Self-Serving Bias (SSB). Accordingly, two hypotheses were developed and tested through two one-way ANOVAs: (1) individuals with high CSE have greater self-leadership compared to individuals with low and average CSE; and (2) individuals with great self-leadership are more inclined to be victims of the self-serving bias compared to individuals with low and average CSE.

The outcomes of the ANOVAs fully confirmed our two hypotheses. In fact, they showed that CSE powerfully affects self-leadership: the higher the evaluation of the self, the greater the self-leadership behavior characterizing the decision makers. This scenario, in line with prior literature on CSE (Hollenbeck et al. 1988; Judge et al. 1998; Judge and Bono 2001; Silvester et al. 2002), establishes that decision makers with a high degree of CSE are, in the long run, likely to retain efforts towards their ambitions with remarkable consequences in their working experience, remuneration and social prestige (Cristofaro 2017b). Thanks to the result emerging from the test of the first hypothesis, the self-leadership literature is advanced and enhanced with regard to the relationship with self-efficacy. Indeed, prior literature found that self-leadership, thanks to the adopted strategies, influences self-efficacy-as demonstrated by Latham and Latham and Frayne (1989), Prussia et al. (1998), and Saks and Ashforth (1996). To that, we add that self-leadership is basically influenced by the self-efficacy trait because this is one of the four pillars of the CSE construct (Cristofaro et al. 2020). In practice, a high self-efficacy trait leads to an increase in self-leadership that, in turn, increases self-efficacy in a co-evolutionary fashion. Thanks to this result, the self-leadership literature focusing on the influence of personality traits is strengthened. For example, Williams et al. (1995) and Williams (1997) have proved a meaningful correlation between the judgment (planful and organized) and sensing (precise and practical) traits and self-leadership; also Stewart Greg L. and Cardy (1996) indicated a significant level of correlation $(p<0.01)$ between conscientiousness and the self-leadership attitude, which is also confirmed by Houghton et al. (2004), who also found a positive relation between self-leadership and extraversion. Thus, in summarizing, we want to underline the fact that it is evident how CSE represents a powerful trait in order to influence the personality that, consequently, affects the self-leadership attitude both on the personal and professional sides. From that, it emerges that CSE is a personality trait that works as an antecedent of self-leadership, reinforcing-by studying a personality trait that has not been ever considered in self-leadership literature-the assumption that: "self-leadership represents a unique constellation of strategies that are founded upon, related to, and yet distinct from these various theories as well as from various personality traits" (Neck and Houghton 2006, p. 275). 
Of course, the reinforcing co-evolutionary mechanism that has been advanced can lead to a vicious cycle in which the self-leadership behavior of people with high CSE brings, in turn, a very high self-efficacy (Hiller and Hambrick 2005); this too strong belief in an individual's own capabilities can lead to falling into cognitive biases.

In this regard, results of the test of the second hypothesis have shown that individuals with strong self-leadership are more likely to be victim of SSB. This happens because people with strong self-leadership continuously look to establish, preserve, and augment their positive self-image (Kwan et al. 2004). From this result, it is possible to argue that those who pursue, even if indirectly, behaving in a way aimed at reaching laudatory outcomes are likely to attribute successes internally and attribute failures externally, in line with what was previously supposed by several scholars, such as Silver et al. (1995), Campbell and Campbell and Sedikides (1999), Alicke and Sedikides (2009), and Sedikides and Alicke (2012). This result reinforces the stream of studies that advanced self-efficacy, one of the four pillars of CSE, has a negative facet due to conducting cognitive errors see (Powers 1973, 1991) —in contrast with the works of Bandura (1986, 1997; Bandura et al. 1999) that assumed a positive influence of self-efficacy on task performance. Indeed, Vancouver et al. (2002), through two laboratory experiments with 87 and 104 undergraduates, respectively, found that self-efficacy has a negative influence on performance, explained by the fact that self-efficacy leads to the cognitive error of overconfidence, which increases the likelihood of committing logic errors during tasks. However, in the proposed contribution, the link between CSE, self-leadership, SSB, and task performance has not been considered; so, self-efficacy is supposed as a 'negative' influence of high self-leadership because it leads to a cognitive error substantiated by the SSB — without due consideration of task performance. However, other works suggested that people with an optimistic explanatory style, oriented to the external attribution of failures, can perform better than people with a pessimistic explanatory style, who make internal attributes of failures (Gillham et al. 2001). From that, future research can expand the results of this work to try to also measure the task performance of individuals present in the sample.

Regarding the originality of this work and its added value, this is the first paper-to the best of the authors' knowledge-on the relationship between CSE and self-leadership with regard to decision making in general, and with cognitive biases in particular. The new advanced relationships between self-leadership and CSE, as well as self-leadership and SSB, give us the opportunity to forecast the consequences deriving from mangers' personality traits and, in turn, the behavior of decision makers. In doing that, this study strengthens what has been recently discovered by Cristofaro et al. (2020) with regard to the relationship between CSE and decision making. In particular, these scholars pointed out that teams characterized by a large degree of CSE are more inclined towards both average and low CSE and risk tumbling into the overconfidence bias. Their analysis is entirely supported by past research in this area, highlighting how teams characterized by a large degree of CSE misjudge their skills, tending to bias the decision-making process (Abatecola et al. 2018; Abatecola and Cristofaro 2019). In brief, this paper also advances the research on CSE and managerial decision making, adding results to the stream of research that perceives this complex personality trait as not always desirable for managerial decision-making processes. From this speculation and from the discovered relationships, some future research questions arise: Are there other biases activated by the presence of high or low self-leadership of managers? What is the threshold level at which self-leadership passes from having a positive influence to a negative one in managerial decision-making processes? These questions represent just a few examples of the large scale of the sphere of application of self-leadership in managerial decision making.

According to the disclosed results, we can also derive some meaningful managerial implications. Leaders and human resource managers should be aware that managers with a high level of CSE are also likely to have high self-leadership and may fall into cognitive biases. So, it is suggested that the CSE level of managers within organizations should be monitored, in order to have the opportunity to judiciously create the best firm architecture possible to reduce the presence of cognitive biases and reach superior decisional and organizational results. In addition, to take control of the 
influences of high CSE and self-leadership, it is also suggested to improve the quantity and quality of controls of the decision-making process; this can be done through the post-implementation, with regard to decision-making processes, of the quality control checklist advanced by Kahneman et al. (2011). The checklist is a 12-item questionnaire in which each question posed to decision makers is aimed at identifying-before making an important decision - the occurrence of a cognitive bias within decision-making processes (Cristofaro 2017c). Moreover, managers of organizations should be aware of the fact that high self-leadership can lead to dysfunctional effects, such as falling into cognitive biases; according to that, training programs aimed at improving the self-leadership of managers should also show the counter value of high self-leadership. However, it is also true that, under some circumstances, biases can lead to results and performances that are greater than the ones reached through the use of other 'more rational' decision-making tools (e.g., inferential statistics) (Gigerenzer and Todd 1999; Luan et al. 2019). Hence, if biases occur within decision-making processes due to the personal characteristics of decision makers, they should be individually assessed in relation to the performed task to identify if their occurrence was totally negative or not.

Despite the accuracy with which this research has been conducted, it suffers from several limitations. First, the test was based on a limited sample population of 93 managers; thus, for future research, it is suggested to use a larger sample and, especially, to extract it from a population coming from different countries in order to be able to study, through a cross cultural analysis, the possible fluctuation of the interaction among CSE, self-leadership, and cognitive biases. Secondly, the 93 managers were asked to complete questionnaires to show their CSE, self-leadership, and SSB tendencies; even if questionnaires are widely recognized as a valid and reliable measure if thoroughly developed scientifically, they are always based on self-reporting mechanisms. For future investigations, it is suggested verifying CSE, self-leadership, and cognitive biases relationships through direct observations of the behaviors of managers in real job contexts. Another limitation of this study, stemming from the terms and conditions of the use of Amazon Mechanical Turk in selecting the sample of respondents, lies in not having known in which sector and organizations the sample managers work, as well as not knowing their specific positions. Future research should use less virtually mediated sampling methods so that these sample features are collected. All these limitations represent good starting points for future investigations in order to have a clearer picture of the relationships among CSE, self-leadership, and cognitive biases.

To conclude, the innovative feature of this paper is represented by the previously unexplored trilateral connection between CSE, self-efficacy, and self-leadership; thus, it not only covers the relation between self-leadership and cognitive biases, but also the more general link between self-leadership and managerial decision-making processes.

Author Contributions: Conceptualization, M.C.; methodology, P.L.G.; formal analysis, M.C.; data curation, M.C.; writing—original draft preparation, P.L.G.; writing—review and editing, M.C.; visualization, P.L.G.; supervision, M.C. All authors have read and agreed to the published version of the manuscript.

Funding: This research received no external funding.

Conflicts of Interest: The authors declare no conflict of interest.

\section{Appendix A Core-Self Evaluation Scale}

1 I I am confident I get the success I deserve in life.

2 Sometimes I feel depressed. (reverse grade)

3 When I try, I generally succeed.

$4 \quad$ Sometimes when I fail, I feel worthless. (reverse grade)

$5 \quad$ I complete tasks successfully.

$6 \quad$ Sometimes I do not feel in control of my work. (reverse grade)

$7 \quad$ Overall, I am satisfied with myself.

$8 \quad$ I I am filled with doubts about my competence. (reverse grade)

$9 \quad$ I determine what will happen in my life. 
10 I I do not feel in control of my success in my career. (reverse grade)

11 I I am capable of coping with most of my problems.

$12 \ldots$ There are times when things look pretty bleak and hopeless to me. (reverse grade)

\section{Appendix B Self-Leadership Scale by Houghton and Neck (2002)}

1 I I use my imagination to picture myself performing well on important tasks.

$2 \_$I I establish specific goals for my own performance.

3 Sometimes I find I'm talking to myself (out loud or in my head) to help me deal with difficult problems I face.

$4 \quad$ When I do an assignment especially well, I like to treat myself to something or an activity I especially enjoy.

$5 \_$I I think about my own beliefs and assumptions whenever I encounter a difficult situation.

$6 \quad$ I I tend to get down in my mind when I have performed poorly.

$7 \quad$ I I make a point to keep track of how well I'm doing at work (school).

8 I I focus my thinking on the pleasant rather than the unpleasant aspects of my job (school) activities.

$9 \quad$ I I use written notes to remind myself of what I need to accomplish.

10 I I visualize myself successfully performing a task before I do it.

11 I I consciously have goals in mind for my work efforts.

12 Sometimes I talk to myself (out loud or in my head) to work through difficult situations.

13 When I do something well, I reward myself with a special event such as a good dinner, movie, shopping trip, etc.

14 I I try to mentally evaluate the accuracy of my own beliefs about situations I am having problems with.

15 I I tend to be tough on myself in my thinking when I have not done well on a task.

16 I I am usually aware of how well I'm doing as I perform an activity.

17 _ I try to surround myself with objects and people that bring out my desirable behaviors.

I use concrete reminders (e.g., notes and lists) to help me focus on things I need to accomplish. Sometimes I picture in my mind a successful performance before I actually do a task. I work toward specific goals I have set for myself.

When I'm in difficult situations, I will sometimes talk to myself (out loud or in my head) to help me get through it.

When I have successfully completed a task, I often reward myself with something I like. I openly articulate and evaluate my own assumptions when I have a disagreement with someone else.

I feel guilt when I perform a task poorly.

I pay attention to how well I'm doing in my work.

When I have a choice, I try to do my work in ways that I enjoy rather than just trying to get it over with.

I purposefully visualize myself overcoming the challenges I face.

I think about the goals that I intend to achieve in the future.

I think about and evaluate the beliefs and assumptions I hold.

I sometimes openly express displeasure with myself when I have not done well.

I keep track of my progress on projects I'm working on.

I seek out activities in my work that I enjoy doing.

I often mentally rehearse the way I plan to deal with a challenge before I actually face the challenge. 


\section{References}

Abatecola, Gianpaolo, and Matteo Cristofaro. 2019. Ingredients of sustainable CEO behavior: Theory and practice. Sustainability 11: 1950. [CrossRef]

Abatecola, Gianpaolo, Andrea Caputo, and Matteo Cristofaro. 2018. Reviewing cognitive distortions in managerial decision making. Toward an integrative co-evolutionary framework. Journal of Management Development 37: 409-24. [CrossRef]

Ajzen, Icek. 2005. Attitudes, Personality, and Behavior. London: McGraw-Hill Education.

Alicke, Mark D., and Constantine Sedikides. 2009. Self-enhancement and self-protection: What they are and what they do. European Review of Social Psychology 20: 1-48. [CrossRef]

Allen, Mark S., Davina A. Robson, Luc J. Martin, and Sylvain Laborde. 2020. Systematic review and meta-analysis of self-serving attribution biases in the competitive context of organized sport. Personality and Social Psychology Bulletin 46: 1027-43. [CrossRef] [PubMed]

Asakereh, Ahmad, and Nouroddin Yousofi. 2018. Reflective Thinking, Self-Efficacy, Self-Esteem and Academic Achievement of Iranian EFL Students in Higher Education: Is there a Relationship? International Journal of Educational Psychology 7: 68-89. [CrossRef]

Bandura, Albert. 1986. The explanatory and predictive scope of self-efficacy theory. Journal of Social and Clinical Psychology 4: 359-73. [CrossRef]

Bandura, Albert. 1997. Self-Efficacy: The Exercise of Control. New York: NH Freeman.

Bandura, Albert, William H. Freeman, and Richard Lightsey. 1999. Self-Efficacy: The Exercise of Control. New York: MacMillan Publishers.

Barker, James R. 1993. Tightening the iron cage: Concertive control in self-managing teams. Administrative Science Quarterly 38: 408-37. [CrossRef]

Bass, Bernard M., and Ralph M. Stogdill. 1990. Bass E Stogdill's Handbook of Leadership: Theory, Research, and Managerial Applications. New York: Free Press.

Baumeister, Roy F., Todd F. Heatherton, and Dianne M. Tice. 1993. When ego threats lead to self-regulation failure: Negative consequences of high self-esteem. Journal of Personality and Social Psychology 64: 141-56. [CrossRef]

Baumeister, Roy F., Laura Smart, and Joseph M. Boden. 1996. Relation of threatened egotism to violence and aggression: The dark side of high self-esteem. Psychological Review 103: 5. [CrossRef] [PubMed]

Behfar, Kristin J., Randall S. Peterson, Elizabeth A. Mannix, and William M. K. Trochim. 2008. The critical role of conflict resolution in teams: A close look at the links between conflict type, conflict management strategies, and team outcomes. Journal of Applied Psychology 93: 170-88. [CrossRef]

Blaine, Bruce, and Jennifer Crocker. 1993. Self-esteem and self-serving biases in reactions to positive and negative events: An integrative review. In Self-Esteem: The Puzzle of Low Self-Regard. Edited by Roy F. Baumeister. Boston: Springer, pp. 55-85.

Busic-Sontic, Ante, Natalia V. Czap, and Franz Fuerst. 2017. The role of personality traits in green decision making. Journal of Economic Psychology 62: 313-28. [CrossRef]

Campbell, Keith W., and Constantine Sedikides. 1999. Self-threat magnifies the self-serving bias: A meta-analytic integration. Review of General Psychology 3: 23-43. [CrossRef]

Chen, Gilad, Stanley M. Gully, and Dov Eden. 2001. Validation of a new general self-efficacy scale. Organizational Research Methods 4: 62-83. [CrossRef]

Chin, Phaik N., Kean S. Ch'ng, and Salmi M. Isa. 2018. The effect of self-serving bias on trading decisions and its solution mechanisms: An experimental study. Global Business \& Management Research 10: 67-81.

Cohen, Susan G., and Gerald E. Ledford. 1994. The effectiveness of self-managing teams: A quasi-experiment. Human Relations 47: 13-44. [CrossRef]

Cohen, Susan G., Lei Chang, and Gerald E. Ledford. 1997. A hierarchical construct of self-management leadership and its relationship to quality of work life and perceived work group effectiveness. Personnel Psychology 50: 275-308. [CrossRef] 
Combs, James G., Yongmei Liu, Angela Hall, and David Ketchen. 2006. How much do high-performance work practices matter? A meta-analysis of their effects on organizational performance. Personnel Psychology 59: 501-28. [CrossRef]

Cordery, John L., Walter S. Mueller, and Leigh M. Smith. 1991. Attitudinal and behavioral effects of autonomous group working: A longitudinal field study. Academy of Management Journal 34: 464-76.

Cristofaro, Matteo. 2016. Cognitive styles in dynamic decision making. A laboratory experiment. International Journal of Management and Decision Making 15: 53-82.

Cristofaro, Matteo. 2017a. Herbert Simon's bounded rationality: Its evolution in management and cross-fertilizing contribution. Journal of Management History 23: 170-90. [CrossRef]

Cristofaro, Matteo. 2017b. Candidates' attractiveness in selection decisions: A laboratory experiment. Baltic Journal of Management 12: 390-407. [CrossRef]

Cristofaro, Matteo. 2017c. Reducing biases of decision-making processes in complex organizations. Management Research Review 40: 270-91. [CrossRef]

Cristofaro, Matteo. 2018. Processi Cognitivi e Decisioni Aziendali. Evidenze di Razionalità Limitata. Roma: Aracne.

Cristofaro, Matteo. 2019. The role of affect in management decisions: A systematic review. European Management Journal 37: 6-17. [CrossRef]

Cristofaro, Matteo. 2020. "I feel and think, therefore I am": An Affect-Cognitive Theory of management decisions. European Management Journal 8: 344-55. [CrossRef]

Cristofaro, Matteo, Pier Luigi Giardino, and Luna Leoni. 2020. The influence of core self-evaluations on group decision making processes: A laboratory experiment. Administrative Sciences 10: 29. [CrossRef]

D'Aveni, Richard A., and Ian C. MacMillan. 1990. Crisis and the content of managerial communications: A study of the focus of attention of top managers in surviving and failing firms. Administrative Science Quarterly 35: 634-57. [CrossRef]

De Jong, Ad, Ko de Ruyter, and Martin Wetzels. 2006. Linking employee confidence to performance: A study of self-managing service teams. Journal of the Academy of Marketing Science 34: 576-87. [CrossRef]

DeVaro, Jed. 2006. Teams, autonomy, and the financial performance of firms. Industrial Relations 45: $217-69$. [CrossRef]

Driskell, James E., Carolyn Copper, and Aidan Moran. 1994. Does mental practice enhance performance? Journal of Applied Psychology 79: 481. [CrossRef]

Dunning, David. 1999. A newer look: Motivated social cognition and the schematic representation of social concepts. Psychological Inquiry 10: 1-11. [CrossRef]

Edmondson, Amy C., and Stacy E. McManus. 2007. Methodological fit in management field research. Academy of Management Review 32: 1246-64. [CrossRef]

Elmuti, Dean, and Yunus Kathawala. 1997. Self-managing teams, quality of work life, and productivity: A field study. American Journal of Business 12: 19-25. [CrossRef]

Erez, Amir, and Timothy A. Judge. 2001. Relationship of core self-evaluations to goal setting, motivation, and performance. Journal of Applied Psychology 86: 1270-79. [CrossRef] [PubMed]

Field, Andy. 2013. Discovering Statistics using IBM SPSS Statistics. London: Sage.

Frayne, Colette A., and John M. Geringer. 2000. Self-management training for improving job performance: A field experiment involving salespeople. Journal of Applied Psychology 85: 366-372. [CrossRef]

Frayne, Colette A., and Gary P. Latham. 1987. Application of social-learning theory to employee self-management of attendance. Journal of Applied Psychology 72: 387-92. [CrossRef]

Fredendall, Lloyd D., and Charles R. Emery. 2003. Productivity increases due to the use of teams in service garages. Journal of Managerial Issues 15: 221-42.

Gardner, Donald G., and Jon L. Pierce. 1998. Self-esteem and self-efficacy within the organizational context. Group and Organization Management 23: 48-70. [CrossRef]

Gigerenzer, Gerd, and Peter M. Todd. 1999. Fast and frugal heuristics: The adaptive toolbox. In Evolution and Cognition. Simple Heuristics that Make Us Smart. Edited by Gerd Gigerenzer, Peter M. Todd and The ABC Research Group. Oxford: Oxford University Press, pp. 3-34.

Gillham, Jane E., Andrew J. Shatté, Karen J. Reivich, and Martin E. P. Seligman. 2001. Optimism, pessimism, and explanatory style. In Optimism \& Pessimism: Implications for Theory, Research, and Practice. Edited by Edward C. Chang. Washington, DC: American Psychological Association, pp. 53-75. 
Gilson, Lucy, and Christina E. Shalley. 2004. A little creativity goes a long way: An examination of teams' engagement in creative processes. Journal of Management 30: 453-70. [CrossRef]

Goldsby, Elizabeth, Michael Goldsby, Cristopher B. Neck, and Crishopher P. Neck. 2020. Under pressure: Time management, self-leadership, and the nurse manager. Administrative Sciences 10: 38. [CrossRef]

Greenberg, Jerald. 1991. Motivation to inflate performance ratings: Perceptual bias or response bias? Motivation and Emotion 15: 81-97. [CrossRef]

Greenberg, Jerald, Tom Pyszczynski, and Sheldon Solomon. 1982. The self-serving attributional bias: Beyond self-presentation. Journal of Experimental Social Psychology 18: 56-67. [CrossRef]

Greenwald, Anthony G. 1980. The totalitarian ego: Fabrication and revision of personal history. American Psychologist 35: 603. [CrossRef]

Hammond, John S., Ralph L. Keeney, and Howard Raiffa. 1998. The hidden traps in decision making. Harvard Business Review 76: 47-58. [PubMed]

Hayward, Mathew L., and Donald C. Hambrick. 1997. Explaining the premiums paid for large acquisitions: Evidence of CEO hubris. Administrative Science Quarterly 42: 103-27. [CrossRef]

Heider, Fritz. 1958. The Psychology of Interpersonal Relation. New York: Wiley.

Hiller, Nathan J., and Donald C. Hambrick. 2005. Conceptualizing executive hubris: The role of hyper core self-evaluations in strategic decision-making. Strategic Management Journal 26: 297-319. [CrossRef]

Hollenbeck, John R., Ellen M. Whitener, and Karen E. Pauli. 1988. An empirical note on the interaction of personality and aptitude in personnel selection. Journal of Management 14: 441-51. [CrossRef]

Houghton, Jeffrey D., and Christopher P. Neck. 2002. The revised self-leadership questionnaire. Journal of Managerial Psychology 17: 672-91. [CrossRef]

Houghton, Jeffery D., T. W. Bonham, P. Neck Christopher, and Singh Kusum. 2004. The relationship between self-leadership and personality: A comparison of hierarchical factor structures. Journal of Managerial Psychology 19: 427-41. [CrossRef]

Humphrey, Stephen E., John R. Hollenbeck, Christopher J. Meyer, and Daniel R. Ilgen. 2007. Trait configurations in self-managed teams: A conceptual examination of the use of seeding for maximizing and minimizing trait variance in teams. Journal of Applied Psychology 92: 885-92. [CrossRef]

Judge, Timothy A., and Joyce E. Bono. 2001. Relationship of core self-evaluations traits: Self-esteem, generalized self-efficacy, locus of control, and emotional stability with job satisfaction and job performance: A meta-analysis. The Journal of Applied Psychology 86: 80-92. [CrossRef]

Judge, Timothy A., and Charlice Hurst. 2008. How the rich and happy get richer and happier: Relationship of core self-evaluations to trajectories in attaining work success. Journal of Applied Psychology 93: 849-63. [CrossRef] [PubMed]

Judge, Timothy A., Edwin A. Locke, and Cathy C. Durham. 1998. The dispositional causes of job satisfaction: A core evaluations approach. Journal of Applied Psychology 83: 17-34. [CrossRef]

Judge, Timothy A., Carl J. Thoresen, Vladimir Pucik, and Theresa M. Welbourne. 1999. Managerial coping with organizational change: A dispositional perspective. Journal of Applied Psychology 84: 107-22. [CrossRef]

Judge, Timothy A., Amir Erez, Joyce E. Bono, and Carl J. Thoresen. 2003. The Core Self-Evaluations scale (CSE): Development of a measure. Personnel Psychology 56: 303-31. [CrossRef]

Judge, Timothy A., Charlice Hurst, and Lauren S. Simon. 2009. Does it pay to be smart, attractive, or confident or all three)? Relationships among general mental ability, physical attractiveness, core self-evaluations, and income. The Journal of Applied Psychology 94: 742-55. [CrossRef]

Kahneman, Daniel, and Amos Tversky. 1974. Subjective probability: A judgment of representativeness. In The Concept of Probability in Psychological Experiments. Edited by Carl-Axel Axen and Stael Von Holstein. Heidelberg: Springer, pp. 25-48.

Kahneman, Daniel, and Amos Tversky. 1979. Prospect theory: An analysis of decisions under risk. Econometrica 47: 263-91. [CrossRef]

Kahneman, Daniel, Dan Lovallo, and Oliver Sibony. 2011. The big idea. Before you make that big decision. Harvard Business Review 89: 50-60. [PubMed]

Keusch, Thomas, Laury H. Bollen, and Harold F. Hassink. 2012. Self-serving bias in annual report narratives: An empirical analysis of the impact of economic crises. European Accounting Review 21: 623-48. [CrossRef] 
Kim, Kwanghyun, In-Sue Oh, Dan S. Chiaburu, and Kenneth G. Brown. 2012. Does positive perception of oneself boost learning motivation and performance? International Journal of Selection and Assessment 20: 257-71. [CrossRef]

Kwan, Virginia S., Oliver P. John, David A. Kenny, Michael H. Bond, and Richard W. Robins. 2004. Reconceptualizing individual differences in self-enhancement bias: An interpersonal approach. Psychological Review 111: 94. [CrossRef]

Lane, John, Andrew M. Lane, and Anna Kyprianou. 2004. Self-efficacy, self-esteem, and their impact on academic performance. Social Behavior and Personality: An International Journal 32: 247-56. [CrossRef]

Langfred, Claus W. 2004. Too much of a good thing? Negative effects of high trust and individual autonomy in self-managing teams. Academy of Management Journal 47: 385-99.

Langfred, Claus W. 2005. Autonomy and performance in teams: The multilevel moderating effect of task interdependence. Journal of Management 31: 513-29. [CrossRef]

Langfred, Claus W. 2007. The downside of self-management: A longitudinal study of the effects of conflict on trust, autonomy, and task interdependence in self-managing teams. Academy of Management Journal 50: 885-900. [CrossRef]

Larwood, Laurie, and William Whittaker. 1977. Managerial myopia: Self-serving biases in organizational planning. Journal of Applied Psychology 62: 194. [CrossRef]

Latham, Gary P., and Colette A. Frayne. 1989. Self-management training for increasing job attendance: A follow-up and a replication. Journal of Applied Psychology 74: 411-16. [CrossRef]

Leary, Mark R., and Roy F. Baumeister. 2000. The nature and function of self-esteem: Sociometer theory. In Advances in Experimental Social Psychology. Cambridge: Academic Press, vol. 32, pp. 1-62.

Libby, Robert, and Kristina Rennekamp. 2012. Self-serving attribution bias, overconfidence, and the issuance of management forecasts. Journal of Accounting Research 50: 197-231. [CrossRef]

Luan, Shenghua, Jochen Reb, and Gerd Gigerenzer. 2019. Ecological rationality: Fast-and-frugal heuristics for managerial decision making under uncertainty. Academy of Management Journal 62: 1735-59. [CrossRef]

Manz, Charles C. 1983. The Art of Self-Leadership: Strategies for Personal Effectiveness in Your Life and Work. Englewood Cliffs: Prentice-Hall.

Manz, Charles C. 1986. Self-leadership: Toward an expanded theory of self-influence processes in organizations. Academy of Management Review 11: 585-600. [CrossRef]

Manz, Charles C., and Christopher P. Neck. 1991. Inner leadership: Creating productive thought patterns. The Executive 5: 87-95. [CrossRef]

Manz, Charles C., and Christopher P. Neck. 2004. Mastering Self-Leadership: Empowering Yourself for Personal Excellence. Upper Saddle River: Pearson Prentice-Hall.

Manz, Charles C., and Henry P. Sims Jr. 1986. Leading self-managed groups: A conceptual analysis of a paradox. Economic and Industrial Democracy 7: 141-65. [CrossRef]

Manz, Charles C., and Henry P. Sims Jr. 1987. Leading workers to lead themselves: The external leadership of self-managing work teams. Administrative Science Quarterly 32: 106-28. [CrossRef]

Manz, Charles C., and Henry P. Sims Jr. 2001. The New superLeadership: Leading Others to Lead Themselves. San Francisco: Berrett-Koehler.

Manz, Charles C., Frank M. Shipper, and Greg L. Stewart. 2009. Shared influence at W.L. Gore \& Associates. Organizational Dynamics 38: 239-44.

McKinney, Arlise P. 2014. Impact of student goal orientation and self-regulation on learning outcomes. Journal of Organizational Psychology 14: 66-77.

Mezulis, Amy H., Lyb Y. Abramson, Janer S. Hyde, and Benjamin L. Hankin. 2004. Is there a universal positivity bias in attributions? A meta-analytic review of individual, developmental, and cultural differences in the self-serving attributional bias. Psychological Bulletin 130: 711. [CrossRef]

Mturk. 2020. Amazon Mecahnical Turk. Available online: https://www.mturk.com (accessed on 30 August 2020).

Murphy, Susan E., and Ellen A. Ensher. 2001. The role of mentoring support and self-management strategies on reported career outcomes. Journal of Career Development 27: 229-46. [CrossRef]

Neck, Christopher P., and Jeffery D. Houghton. 2006. Two decades of self-leadership theory and research. Journal of Managerial Psychology 21: 270-95. [CrossRef]

Neck, Christopher P., and Charles C. Manz. 1992. Thought self-leadership: The impact of self-talk and mental imagery on performance. Journal of Organizational Behavior 12: 681-99. [CrossRef] 
Neck, Christopher P., and Charles C. Manz. 1996. Thought self-leadership: The impact of mental strategies training on employee behavior, cognition, and emotion. Journal of Organizational Behavior 17: 445-67. [CrossRef]

Neck, Christopher P., and Charles C. Manz. 2007. Mastering Self-Leadership: Empowering Yourself for Personal Excellence. Upper Saddle River: Pearson Prentice-Hall.

Neubert, Mitchell J., and Ju-Chien C. Wu. 2006. An investigation of the generalizability of the Houghton and Neck Revised Self-Leadership Questionnaire to a Chinese context. Journal of Managerial Psychology 21: 360-73. [CrossRef]

Paniccia, Paola M. A. 2002. Dinamiche Temporali e Cognitive Nell'approccio Sistemico al Governo dell'impresa. Padova: Cedam.

Paolacci, Gabriele, Jesse Chandler, and Panagiotis G. Ipeirotis. 2010. Running experiments on Amazon Mechanical Turk. Judgment and Decision Making 5: 411-19.

Paunova, Minna. 2017. Who gets to lead the multinational team? An updated status characteristics perspective. Human Relations 70: 883-907. [CrossRef]

Powers, William T. 1973. Behavior: The Control of Perception. Chicago: Aldine.

Powers, William T. 1991. Commentary on Bandura's "Human Agency". American Psychologist 46: 151-53. [CrossRef]

Prussia, Gregory E., Joe S. Anderson, and Charles C. Manz. 1998. Self-leadership and performance outcomes: The mediating influence of self-efficacy. Journal of Organizational Behavior 19: 523-38. [CrossRef]

Raabe, Babette, Michael Frese, and Terry A. Beehr. 2007. Action regulation theory and career self-management. Journal of Vocational Behavior 70: 297-311. [CrossRef]

Saks, Alan M., and Blake E. Ashforth. 1996. Proactive socialization and behavioral self-management. Journal of Vocational Behavior 48: 301-23. [CrossRef]

Scherbaum, Charles A., Yochi Cohen-Charash, and Michael J. Kern. 2006. Measuring general self-efficacy: A comparison of three measures using item response theory. Educational and Psychological Measurement 66: 1047-63. [CrossRef]

Sedikides, Constantine. 1993. Assessment, enhancement, and verification determinants of the self-evaluation process. Journal of Personality and Social Psychology 65: 317. [CrossRef]

Sedikides, Constantine, and Mark D. Alicke. 2012. Self-Enhancement and Self-Protection Motives. In Oxford Library of Psychology. The Oxford Handbook of Human Motivation. Edited by Richard M. Ryan. Oxford: Oxford University Press, pp. 303-22.

Sedikides, Constantine, and Michael J. Strube. 1995. The multiply motivated self. Personality and Social Psychology Bulletin 21: 1330-35. [CrossRef]

Sedikides, Constantine, and Michael J. Strube. 1997. Self-evaluation: To thine own self be good, to thine own self be sure, to thine own self be true, and to thine own self be better. In Advances in Experimental and Social Psychology. Edited by Mark P. Zanna. New York: Academic Press, vol. 29, pp. 209-69.

Sedikides, Constantine, Keith W. Campbell, Glenn D. Reeder, and Andrew J. Elliot. 1998. The self-serving bias in relational context. Journal of Personality and Social Psychology 74: 378. [CrossRef]

Silver, William S., Therence R. Mitchell, and Marilyn E. Gist. 1995. Responses to successful and unsuccessful performance: The moderating effect of self-efficacy on the relationship between performance and attributions. Organizational Behavior and Human Decision Processes 62: 286-99. [CrossRef]

Silvester, Joanne, Fiona M. Anderson-Gough, Neil R. Anderson, and Afandi R. Mohamed. 2002. Locus of control, attributions and impression management in the selection interview. Journal of Occupational and Organizational Psychology 75: 59-76. [CrossRef]

Smith, Eliot R., Diane M. Mackie, and Heather M. Claypool. 2007. Social Psychology. London: Psychology Press.

Stajkovic, Alexander D., and Fred Luthans. 1998. Self-efficacy and work-related performance: A meta-analysis. Psychological Bulletin 124: 240-61. [CrossRef]

Stevenson, Regan M., Michael P. Ciuchta, Chaim Letwin, Jenni M. Dinger, and Jeffrey B. Vancouver. 2019. Out of control or right on the money? Funder self-efficacy and crowd bias in equity crowdfunding. Journal of Business Venturing 34: 348-67. [CrossRef]

Stewart, Greg L., and Murray R. Barrick. 2000. Team structure and performance: Assessing the mediating role of intrateam process and the moderating role of task type. Academy of Management Journal 43: 135-48. 
Stewart Greg L., Kenneth P. Carson, and Robert L. Cardy. 1996. The joint effects of conscientiousness and self-leadership training on employee self-directed behavior in a service setting. Personnel Psychology 49: 143-64. [CrossRef]

Stewart, Greg L., Stephen H. Courtright, and Charles C. Manz. 2011. Self-leadership: A multilevel review. Journal of Management 37: 185-222. [CrossRef]

Stewart, Greg L., Stephen H. Courtright, and Charles C. Manz. 2012. Peer-based control in self-managing teams: Linking rational and normative influence with individual and group performance. Journal of Applied Psychology 97: 435-47. [CrossRef]

Stewart, Greg L., Stacy L. Astrove, Cody J. Reeves, Eean R. Crawford, and Samantha L. Solimeo. 2017. Those with the most find it hardest to share: Exploring leader resistance to the implementation of team-based empowerment. Academy of Management Journal 60: 2266-93. [CrossRef]

Stewart, Greg L., Stephen H. Courtright, and Charles C. Manz. 2019. Self-leadership: A paradoxical core of organizational behavior. Annual Review of Organizational Psychology and Organizational Behavior 6: 47-67. [CrossRef]

Taylor, Shelley E., and Jonathon D. Brown. 1988. Illusion and well-being: A social psychological perspective on mental health. Psychological Bulletin 103: 193. [CrossRef] [PubMed]

Trist, Eric L., Gerald I. Susman, and Grant R. Brown. 1977. An experiment in autonomous group working in an American underground coal mine. Human Relations 30: 201-36. [CrossRef]

Uhl-Bien, Mary, and George B. Graen. 1998. Individual self-management: Analysis of professionals' self-managing activities in functional and cross-functional teams. Academy of Management Journal 41: 340-50.

Vancouver, Jeffrey B., Charles M. Thompson, Casey E. Tischner, and Dan J. Putka. 2002. Two studies examining the negative effect of self-efficacy on performance. Journal of Applied Psychology 87: 506-16. [CrossRef] [PubMed]

Wall, Toby D., Nigel J. Kemp, Paul R. Jackson, and Chris W. Clegg. 1986. Outcomes of autonomous work groups: A long-term field experiment. Academy of Management Journal 29: 280-304.

Wanberg, Connie R., Theresa M. Glomb, Zhaoli Song, and Sarah Sorenson. 2005. Job-search persistence during unemployment: A 10-wave longitudinal study. Journal of Applied Psychology 90: 411. [CrossRef]

Wang, Zhen, and Haoying Xu. 2019. When and for whom ethical leadership is more effective in eliciting work meaningfulness and positive attitudes: The moderating roles of core self-evaluation and perceived organizational support. Journal of Business Ethics 156: 919-40. [CrossRef]

Watt, Susan E., and Paul R. Martin. 1994. Effect of general self-efficacy expectancies on performance attributions. Psychological Reports 75: 951-61. [CrossRef]

Weary-Bradley, Gifford W. 1978. Self-serving biases in the attribution process: A reexamination of the fact or fiction question. Journal of Personality and Social Psychology 36: 56. [CrossRef]

Weary-Bradley, Gifford. 1979. Self-serving attributional biases: Perceptual or response distortions? Journal of Personality and Social Psychology 38: 348-57.

Weinberg, Robert S., Daniel Gould, and Allen Jackson. 1979. Expectations and performance: An empirical test of Bandura's self-efficacy theory. Journal of Sport Psychology 1: 320-31. [CrossRef]

Williams, Scott. 1997. Personality and self-leadership. Human Resource Management Review 7: 139-55. [CrossRef]

Williams, Robert L., John S. Verble, Donald E. Price, and Benjamin H. Layne. 1995. Relationship of self-management to personality types and indices. Journal of Personality Assessment 64: 494-506. [CrossRef]

Zhang, Yejun, Jian-Min Sun, Cai-Hui Lin, and Hong Ren. 2020. Linking core self-evaluation to creativity: The roles of knowledge sharing and work meaningfulness. Journal of Business and Psychology 35: 257-70. [CrossRef]

Zuckerman, Miron. 1979. Attribution of success and failure revisited, or: The motivational bias is alive and well in attribution theory. Journal of Personality 47: 245-87. [CrossRef]

(C) 2020 by the authors. Licensee MDPI, Basel, Switzerland. This article is an open access article distributed under the terms and conditions of the Creative Commons Attribution (CC BY) license (http://creativecommons.org/licenses/by/4.0/). 